\title{
Medial Thigh Fasciocutaneous Flaps for Reconstruction of the Scrotum following Fournier Gangrene: A case report
}

Rodrigue Mwenibamba ${ }^{1}$, Daniel Safari Nteranya ${ }^{2}$, Augustin Mukakala ${ }^{1}$, Christian Wabene $^{1}$, Angelique Rugendabanga ${ }^{1}$, Fabrice Kibukila ${ }^{1}$, Nathan Mitima ${ }^{1}$, and Jean Claude Niyondiko ${ }^{3}$

${ }^{1}$ Official University of Bukavu

${ }^{2}$ Universite Officielle de Bukavu

${ }^{3}$ University of Burundi

February 5, 2022

\begin{abstract}
Fournier's gangrene, a rapidly progressive necrotizing fasciitis of the perineum and external genitalia remains a medical-surgical emergency. The authors present a case of coverage of a scrotal loss of substance with testicular exposure by a medial fasciocutaneous flap in a fifty years male patient.
\end{abstract}

\section{Hosted file}

Medial Thigh Fasciocutaneous Flaps for Reconstruction of the Scrotum following Fournier Gangrene.docx available at https://authorea.com/users/459042/articles/555442-medial-thigh-fasciocutaneousflaps-for-reconstruction-of-the-scrotum-following-fournier-gangrene-a-case-report 